\title{
Electrophoretically prepared hybrid materials for biopolymer hydrogel and layered ceramic nanoparticles
}

\author{
Gyeong-Hyeon Gwak', Ae-Jin Choi², Yeoung-Seuk Bae ${ }^{2}$, Hyun-Jin Choi ${ }^{2}$ and Jae-Min Oh*
}

\begin{abstract}
Background: In order to obtain biomaterials with controllable physicochemical properties, hybrid biomaterials composed of biocompatible biopolymers and ceramic nanoparticles have attracted interests. In this study, we prepared biopolymer/ceramic hybrids consisting of various natural biopolymers and layered double hydroxide $(\mathrm{LDH})$ ceramic nanoparticles via an electrophoretic method. We studied the structures and controlled-release properties of these materials.
\end{abstract}

Results and discussion: X-ray diffraction (XRD) patterns and X-ray absorption spectra (XAS) showed that LDH nanoparticles were formed in a biopolymer hydrogel through electrophoretic reaction. Scanning electron microscopic (SEM) images showed that the ceramic nanoparticles were homogeneously distributed throughout the hydrogel matrix. An antioxidant agent (i.e., ferulic acid) was loaded onto agarose/LDH and gelatin/LDH hybrids, and the time-dependent release of ferulic acid was investigated via high-performance liquid chromatography (HPLC) for kinetic model fitting.

Conclusions: Biopolymer/LDH hybrid materials that were prepared by electrophoretic method created a homogeneous composite of two components and possessed controllable drug release properties according to the type of biopolymer.

Keywords: Biopolymer, Agarose, Gelatin, Ceramic, Layered double hydroxide, Electrophoretic synthesis, Controlled release

\section{Background}

Biomaterials, in a broad sense of the definition, are materials that can be applied to biological systems. They include materials used in medical devices, artificial tissues/organs, bone cement, dental implants, biosensors, catheters, drug delivery systems, hygiene items, etc. [1-3]. In terms of their material properties, biomaterials can be classified as polymers, metals, ceramics, and hybrid materials. Among them, polymers (e.g., poly(lactic acid) (PLA), poly(glycolic acid) (PGA), and poly(lactic-co-glycolic acid) (PLGA)) have been widely studied for soft tissue applications to recover the structure and function of organs. Polymers are desirable because they possess mechanical flexibility, biodegradability, cellular interaction, easy

\footnotetext{
* Correspondence: jaemin.oh@yonsei.ac.kr

${ }^{1}$ Department of Chemistry and Medical Chemistry, College of Science and Technology, Yonsei University, \#326, Changjo-hall, Wonju Campus,

Yonseidaegil 1, Heungeop-myeon, Wonju, Gangwondo 26493, Republic of Korea

Full list of author information is available at the end of the article
}

modification, etc. $[4,5]$. Natural polymers, like collagen, have been investigated for use as tissue engineering scaffolds [6]. Ceramics are often utilized in hard tissue applications because they have high mechanical strength and chemical stability. For instance, calcium phosphate and hydroxyapatites have been extensively studied for use in mesenchymal stem cell differentiation, bone engineering, and dental implants [7-9]. Metallic biomaterials, such as stainless steel, $\mathrm{Ti}$ alloys, and $\mathrm{Co}-\mathrm{Cr}$ alloys, can be applied in surgical implants or bone tissue engineering applications due to their easy sterilization, high mechanical strength, fracture resistance, and widely available fabrication techniques $[10,11]$.

Recently, hybrid biomaterials consisting of two or more components have been developed in order to achieve synergic effects. For instance, polymer/polymer hybrids of gelatin, alginate, hyaluronate, and chitosan were reported as wound dressings; these materials have controlled porosity and water uptake properties [12]. An agarose/chitosan hybrid that was 
suggested by Z. Cao et al. achieved reasonable mechanical strength and effective neuronal growth in 3D space [13]. C. Du et al. reported a hydroxyapatiteincorporated collagen-ceramic/polymer hybrid that was both bioactive and biodegradable [14]. Y. Ito et al. developed hybrids that were composed of biocompatible and biodegradable poly(3-hydroxybutyrate-co-3-hydroxyvalerate) (PHBV) nanofibers and hydroxyapatite in order to achieve high specific surface area, surface hydrophilicity, and enzyme invasion [15].

In this context, we attempted to prepare polymer/ ceramic hybrids consisting of biopolymer hydrogels and layered ceramic nanomaterials. For the preparation of these materials, we utilized electrophoretic hybridization, in which ceramic particles were grown in situ in a hydrogel matrix, thereby resulting in the uniform distribution of ceramic nanomaterials [16]. As shown in Scheme 1, several natural biopolymers (that are known to form hydrogels) and ceramic nanomaterials (layered double hydroxide (LDH)) were chosen as the candidate materials. Agarose is a biopolymer of polysaccharide chains that can be utilized as the scaffold in tissue engineering [17, 18]. Gelatin is a mixture of peptides and proteins obtained from the partial hydrolysis of natural animal collagen; this is commercially utilized as a biodegradable polymer [6]. Carrageenan is a polysaccharide polymer extracted from red seaweed and is utilized as a gelation agent or drug stabilizer [19]. Xanthan gum is obtained via the fermentation of carbohydrates with Xanthomonas Campestris and is often utilized to control the viscosity of food [20]. Alginate is a characteristic polysaccharide that forms a hydrogel in the presence of divalent metal ions and can be utilized as both wound dressing and scaffolds [21]. Pectins are extracted from the peels of citrus fruits and are widely used as food stabilizers [22]. Hyaluronic acid is used in implant coatings or during ocular surgery due to its high water content in its hydrogel form [23]. The aforementioned biopolymers are known to show a temperature-dependent gel-sol transition and high biocompatibility; thus, they are excellent candidates for use in drug delivery systems and tissue engineering. The ceramic material in this study is layered double hydroxide (LDH), which is composed of positively charged nanosheets and interlayer anions [24]. Due to its biocompatibility and high anionic exchange capacity, LDH has been suggested as a targeted cellular drug delivery carrier or for use in sustained drug release systems.

Herein, we demonstrate possible biopolymer/LDH hybrids made via an electrophoretic method. The obtained hybrids were analyzed in terms of their structure and nanoparticle distribution utilizing X-ray diffraction, X-ray absorption spectroscopy, and electron microscopy. We also investigated the potential of these prepared hybrids in sustained drug release system utilizing an antioxidant agent, ferulic acid, as the model drug.

\section{Method}

\section{Materials}

Agarose (MW: $120 \mathrm{kDa}$ ) was purchased from Bio Basic Inc., Canada. Gelatin (from porcine skin), zinc nitrate hexahydrate $\left(\mathrm{Zn}\left(\mathrm{NO}_{3}\right)_{2} \cdot 6 \mathrm{H}_{2} \mathrm{O}\right)$, aluminum nitrate nonahydrate $\left(\mathrm{Al}\left(\mathrm{NO}_{3}\right)_{3} \cdot 9 \mathrm{H}_{2} \mathrm{O}\right)$, sodium bicarbonate $\left(\mathrm{NaHCO}_{3}\right)$, tris(hydroxymethyl)aminomethane (Tris: $\left.\mathrm{NH}_{2} \mathrm{C}\left(\mathrm{CH}_{2} \mathrm{OH}\right)_{3}\right)$, and the antioxidant agent (ferulic acid $\left.\left(\mathrm{C}_{10} \mathrm{H}_{10} \mathrm{O}_{4}\right)\right)$ were purchased from Sigma-Aldrich Co. LLC, USA. Ammonia water $\left(\mathrm{NH}_{4} \mathrm{OH}\right)$, sodium hydroxide $(\mathrm{NaOH})$, and hydrochloric acid $(\mathrm{HCl})$ were purchased from Daejung Chemicals \& Metals Co. LTD., Korea.

\section{Electrophoresis method}

In order to prepare biopolymer/LDH hybrid materials electrophoretically, a home-made electrophoretic kit was utilized. First, the biopolymer powder (1 wt/v\% for agarose and $2 \mathrm{wt} / \mathrm{v} \%$ for gelatin and the other biopolymers) was dissolved in tris- $\mathrm{HCl}$ buffer $\left(\mathrm{pH}\right.$ 7.4) at $120{ }^{\circ} \mathrm{C}$. Then, the solution was poured into the center of the electrophoretic kit walled by plastic plates and cooled down to room temperature for $4 \mathrm{~h}$ to obtain a cuboidal hydrogel. The cationic metal solution $\left(0.16 \mathrm{M} \mathrm{Zn}^{2+}\right.$ and $\left.0.08 \mathrm{M} \mathrm{Al}^{3+}\right)$ and the anionic solution $(0.08 \mathrm{M} \mathrm{NaHCO}$ and $1 \mathrm{~mL}$ $\mathrm{NH}_{4} \mathrm{OH}$ ), which were precursors for $\mathrm{LDH}$, were located at each side of the cuboidal hydrogel. Then, electrophoresis was operated with $25 \mathrm{~V}$ for $30 \mathrm{~min}$. After reaction, the hydrogel was washed with deionized water and thoroughly dehydrated.

As a reference sample for $\mathrm{LDH}, \mathrm{ZnAl}-\mathrm{CO}_{3}-\mathrm{LDH}$ $\left(\mathrm{Zn}_{2} \mathrm{Al}(\mathrm{OH})_{6}\left(\mathrm{CO}_{3}\right)_{0.5}\right)$ was prepared by conventional coprecipitation method, as reported elsewhere [24]. Typically, the cationic metal solution $\left(0.063 \mathrm{M} \mathrm{Zn}^{2+}\right.$ and $\left.0.0315 \mathrm{M} \mathrm{Al}^{3+}\right)$ was titrated with basic solution $(\mathrm{NaOH}$ and $\mathrm{NaHCO}_{3}$ ) to $\mathrm{pH} \sim 8.5$ with vigorous stirring. After $24 \mathrm{~h}$, white precipitates formed. These were centrifuged, washed by deionized water, and then dried.

\section{Characterization}

Prepared hybrids were characterized by X-ray diffraction (XRD), X-ray absorption spectroscopy (XAS), and field emission scanning electron microscope (FE-SEM). In order to identify the crystal structure of the ceramic particles in the hybrid, XRD patterns and XAS spectra were obtained by Bruker D2 phaser with $\mathrm{Ni}$-filtered $\mathrm{Cu}-\mathrm{K} \alpha$ radiation $(\lambda=1.5406 \AA)$ and at the 7D XAFS beam line at the Pohang Accelerator Laboratory (Pohang, Korea), 

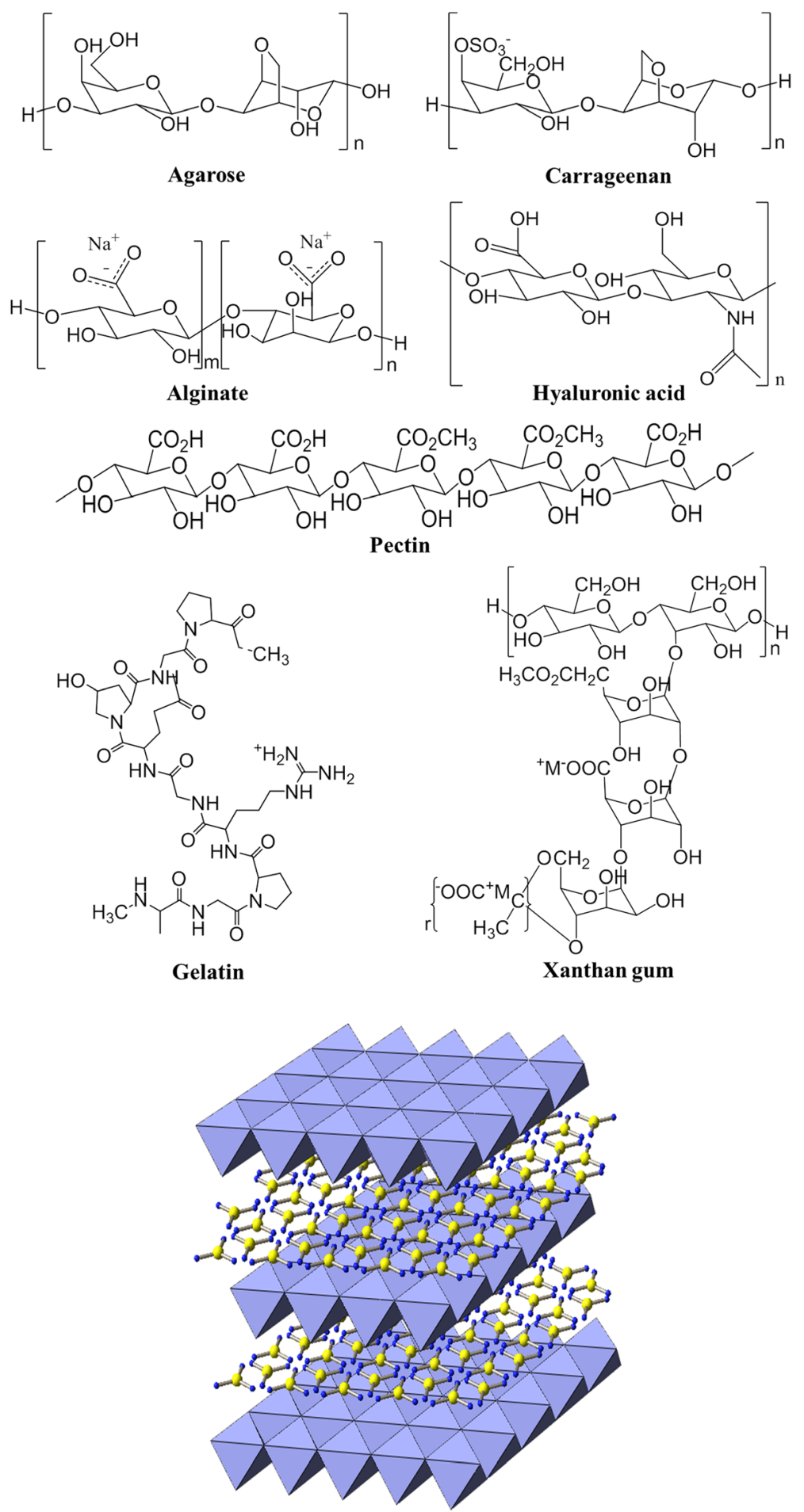

Layered double hydroxide(LDH)

Scheme 1 Schematic molecular structures of biopolymers and LDH nanoparticles

respectively. FE-SEM images, obtained with Hitachi SU70 at the Korea Basic Science Institute (Gangneung Center, Korea), showed the shape and size of LDH nanoparticles in the hybrids.

\section{Sustained release test}

Ferulic acid (FA), which was the model molecule used in our drug delivery system, was dissolved in deionized water and the $\mathrm{pH}$ was adjusted to $7 \sim 8$ for clear 
dissolution. The lyophilized biopolymer/LDH hybrid (approximately $0.5 \mathrm{~g}$ ) was soaked in $50 \mathrm{~mL}$ of the FA solution $(0.05 \mathrm{M})$ for 1 day and then dehydrated. The FA-loaded hybrid was put into $30 \mathrm{~mL}$ of saline and supernatant aliquots were obtained at each time point $(0,5,10,20,30,45,60$, and $120 \mathrm{~min})$ with shaking. After filtration, aliquots were quantified by high-performance liquid chromatography (HPLC: YL9100 YL instrument Co., Ltd.) with $\mathrm{C} 18$ column at $35{ }^{\circ} \mathrm{C}$. A mixed solution of phosphoric acid and acetonitrile (ratio $=7: 3$ ) was used as an eluent. Aliquots were subjected to HPLC analysis at a flow rate of $1.0 \mathrm{~mL} / \mathrm{min}$ at 254 and $320 \mathrm{~nm}$ with a dual-wavelength UV-visible detector. The percentages of the released amounts of FA in the biopolymer/LDH hybrid were obtained and the kinetics were analyzed with the Elovich model (eq. 1).

$$
\mathrm{Qt}=\frac{1}{\beta} \ln (\alpha \beta)+\frac{1}{\beta} \ln (t)
$$

(Qt: release amount at time $t, t:$ time, $\alpha$ and $\beta$ : Elovich constants representing the initial release rate and the overall release rate, respectively.)

\section{Results and discussion}

We chose $\mathrm{LDH}\left(\mathrm{Zn}_{2} \mathrm{Al}(\mathrm{OH})_{6}\left(\mathrm{CO}_{3}\right)_{0.5}\right.$ (Scheme 1$\left.)\right)$ as the ceramic nanoparticle because it is known to a biocompatible inorganic material that can effectively stabilize and control the release kinetics of biologicallyfunctionalized anions $[25,26]$. As candidates for the hydrogel components, we chose several biopolymers that are commonly utilized as biomaterials and form hydrogels via thermoreversibility (Scheme 1). First, we attempted to make hydrogels with $0.5-3.0 \%(\mathrm{wt} / \mathrm{v})$ of the selected biopolymers. This concentration was selected because our preliminary study showed that hydrogels in this range effectively adopt precursors to make ceramic nanoparticles inside hydrogels. As shown in Table 1, most of the biopolymers formed gels within this

Table 1 Hydrogel candidates for the electrophoretic preparation method

\begin{tabular}{llll}
\hline Biopolymer & $\begin{array}{l}\text { Hydrogel } \\
\text { formation }\end{array}$ & $\begin{array}{l}\text { Cuboidal hydrogel } \\
\text { formation }\end{array}$ & $\begin{array}{l}\text { Electrophoretic } \\
\text { hybrid formation }\end{array}$ \\
\hline Agarose & $\circ$ & $\circ$ & $\circ$ \\
Gelatin & $\circ$ & $\circ$ & $\circ$ \\
Carrageenan & $\circ$ & $\circ$ & $\times$ \\
Xanthan gum & $\circ$ & $\circ$ & $\times$ \\
Alginate & $\circ$ (with divalent & $\times$ & $\times$ \\
Pectin & $\circ$ (with divalent & $\times$ & $\times$ \\
& $\quad$ cations) & & \\
Hyaluronic acid & $\times$ & $\times$ & $\times$ \\
\hline
\end{tabular}

concentration range, with the exception of hyaluronic acid. Next, we checked whether or not the hydrogels could be manipulated as cuboidal lumps $(4 \mathrm{~cm} \times 3.5 \mathrm{~cm} \times$ $1 \mathrm{~cm}$ ) in order to apply them to the electrophoretic kit. Unfortunately, neither alginate nor pectin formed $\mathrm{cu}$ boids; instead, they made small and separated gel particles. Thus, we carried out electrophoretic reactions on agarose, gelatin, carrageenan, and xanthan gum. After $30 \mathrm{~min}$ of reaction, we checked for the formation of ceramic nanoparticles by looking for a color change in the hydrogels; the translucent gels turn opaque upon the formation of nanoparticles. While agarose and gelatin clearly showed color changes, carrageenan and xanthan gum gels did not exhibit opacity. Compared to agarose and gelatin, lots of anionic sites in the carrageenan and xanthan gum can be directly coordinated with metal cation-forming complexes, which can hinder the formation of ceramic nanoparticles.

In order to confirm that the particles inside of the hydrogels had a LDH structure, we further characterized the agarose/LDH and gelatin/LDH hybrids with XRD and XAS. Figure 1 shows XRD patterns of the biopolymer hydrogels, hybrids, and conventionally prepared LDH. Dried agarose showed crystalline peaks at $11.15,22.06,32.45,40.90$, and $50.48^{\circ}$; these were attributed to the ordered stacking of polysaccharide rings [27]. However, the agarose/LDH hybrid showed an amorphous pattern that had neither agarose nor LDH peaks. The formation of ceramic LDH nanoparticles inside of the hydrogel perturbed the ordered stacking of polysaccharide, thereby reducing the crystallinity of the hydrogel. The LDH nanoparticles that formed inside of the hydrogel might be too small to be detected in their crystalline form. The dried gelatin showed broad XRD peaks around 8.00 and $20.10^{\circ}$, which correspond to the $\alpha$-helix and triple helical structures [28]. Gelatin/LDH showed an XRD pattern that was similar to gelatin, but the degree of structure perturbation of LDH was less serious in gelatin than in agarose.

Because we could not clearly confirm that the ceramic particles forming inside of the hydrogel were LDHphased particles, we carried out XAS analysis. XAS shows the local structures around certain metal ions, enabling us to determine whether the structure of the particles matched that of LDH. XAS spectra can be divided into two regions: the X-ray absorption near edge structure (XANES) and the extended X-ray absorption fine structure (EXAFS). XANES provides information about metal ions, such as the oxidation number and local symmetry, while EXAFS shows the bond length between the target metal and nearby atoms as well as disorder in coordination bonds. As shown in Fig. 2a, 


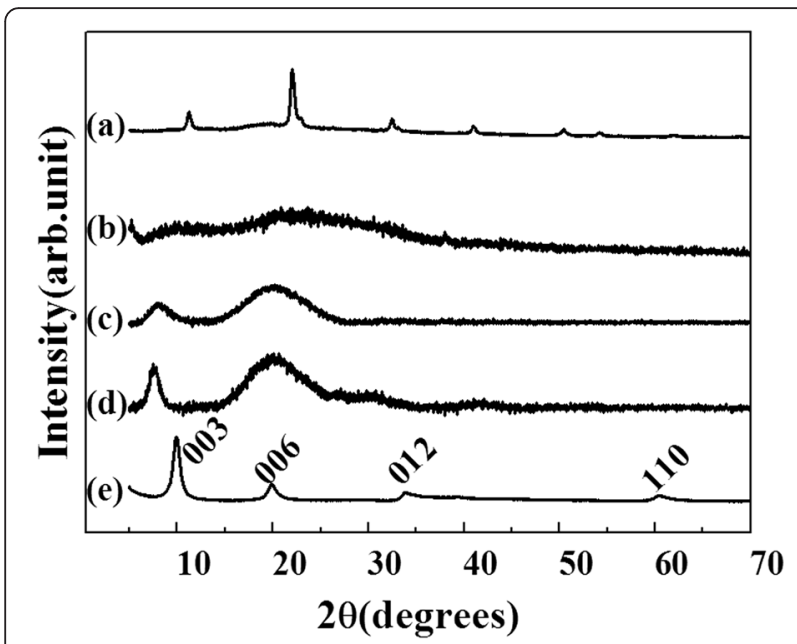

Fig. 1 XRD patterns of (a) agarose film, (b) agarose/LDH, (c) gelatin, (d) gelatin/LDH, and (e) coprecipitated ZnAl-LDH nanoparticles

both the hybrid and ZnAl-LDH showed the main edge of the $\mathrm{Zn} \mathrm{K}$-edge at $9664.08 \mathrm{eV}$; this suggests the existence of the $\mathrm{Zn}$ ion 2+ oxidation state [29]. Because neither XANES spectra showed a pre-edge, $\mathrm{Zn}$ (II) in both samples was determined to have fully-occupied 3d electrons and to possess octahedral symmetry [30, 31]. Generally, $\mathrm{Zn}$ (II) in biological circumstances tends to possess tetrahedral symmetry, while the LDH phase contains $\mathrm{Zn}(\mathrm{II})$ at its octahedral sites. Thus, we can infer that the hybrid contained LDH nanoparticles. Although the XANES spectra of ZnAl-LDH and the hybrid showed similar patterns, we found that the secondary peak (around $9685 \mathrm{eV}$ ) and the oscillation pattern beyond $9680 \mathrm{eV}$ were slightly different according to the sample (Fig. 2a). This subtle difference was further evaluated with Fourier transformed-EXAFS spectra. As shown in Fig. 2b, spectra of both samples showed firstshell peak at $\mathrm{R}=1.63 \AA$ (non-phase-shift-corrected) and second-shell peak at $\mathrm{R}=2.76 \AA$ (non-phase-shift-corrected). These had similar shapes, which suggested that the inorganic particles inside of the hydrogel have the same crystal structure as ZnAl-LDH. In order to quantitatively evaluate the structure, including features like the bond lengths and structural disorder caused by thermal vibration, we carried out FEFF6-code analyses. The firstand second-shell peaks were attributed to $\mathrm{Zn}-\mathrm{O}$ and $\mathrm{Zn}$ ( $\mathrm{Zn}$ or $\mathrm{Al})$, respectively. The calculated bond lengths of $\mathrm{Zn}-\mathrm{O}$ were $2.09 \AA$ and $2.06 \AA$ for conventional $\mathrm{ZnAl}$ $\mathrm{LDH}$ and hybrid $\mathrm{LDH}$, respectively. Those of $\mathrm{Zn}-(\mathrm{Zn}$ or Al) were $3.15 \AA$ and $3.19 \AA$, respectively. The DebyeWaller factors, which reflect the structural disorder, were 0.007 (first-shell) and 0.017 (second-shell) for conventional LDH and 0.010 (firs- shell) and 0.029 (secondshell) for the nanoparticles in the hybrid. The slightly
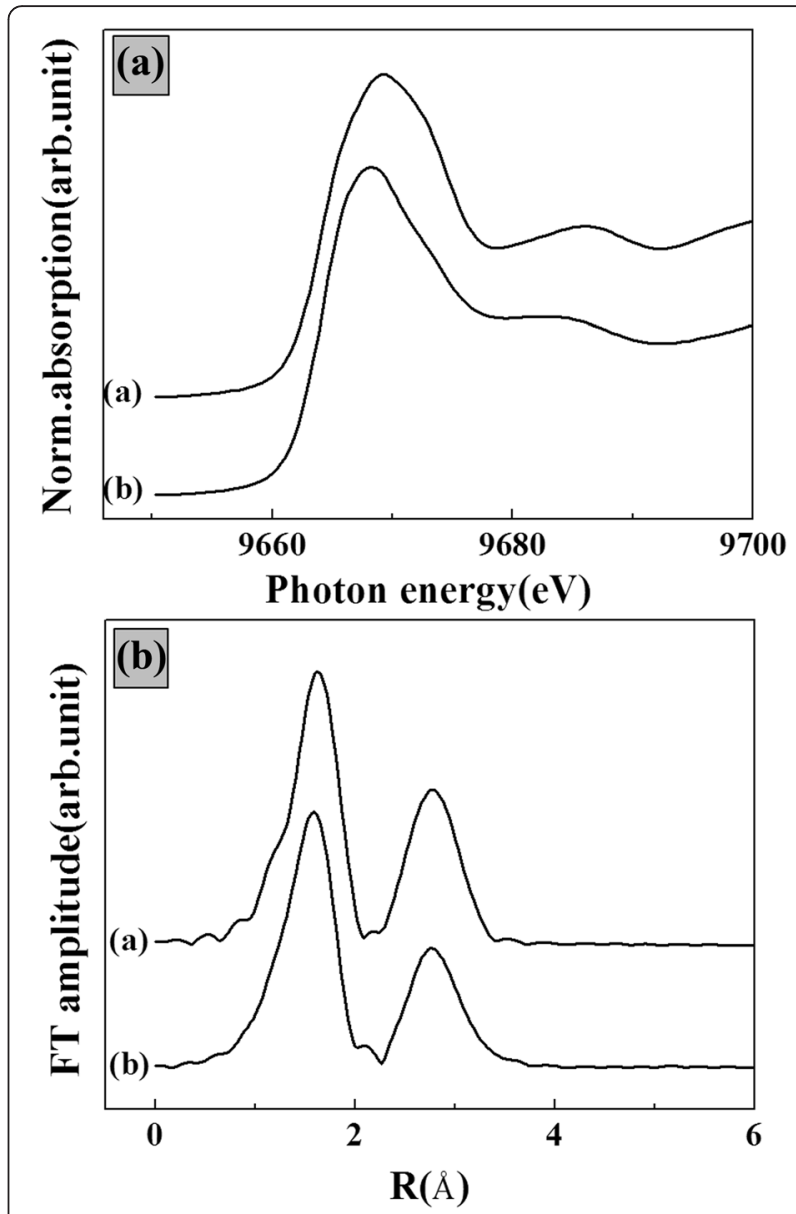

Fig. 2 a Zn K-edge XANES spectra and b Fourier-transformed EXAFS spectra for (a) coprecipitated ZnAl-LDH nanoparticles and (b) agarose/LDH

different bond lengths and increase in the Debye-Waller factor for the hybrids suggested that the LDH structure inside of the hybrid was slightly distorted. This difference is thought to originate from the small particle size of $\mathrm{LDH}$ inside of the hydrogel as compared to those of the conventionally prepared ZnAl-LDH.

In order to investigate the size and morphology of agarose/LDH, as compared to conventionally prepared ZnAl-LDH particles, we carried out SEM measurements (Fig. 3). Although conventionally prepared LDHs do not clearly show primary particles due to agglomeration (Fig. 3(a)), we can determine that the primary particle size is $\sim 20 \mathrm{~nm}$ in the magnified images (Fig. 3(b)). SEM images of agarose/LDH showed both a polymeric phase with a smooth surface (dotted circle in Fig. 3(c)) [8] and a widely distributed particulate phase. We magnified the particulate phase to observe the small size $(20-30 \mathrm{~nm})$ and spherical shape of the LDH nanoparticles inside of the hydrogel. The significantly smaller size of LDH particles in agarose/LDH, as compared to conventional 

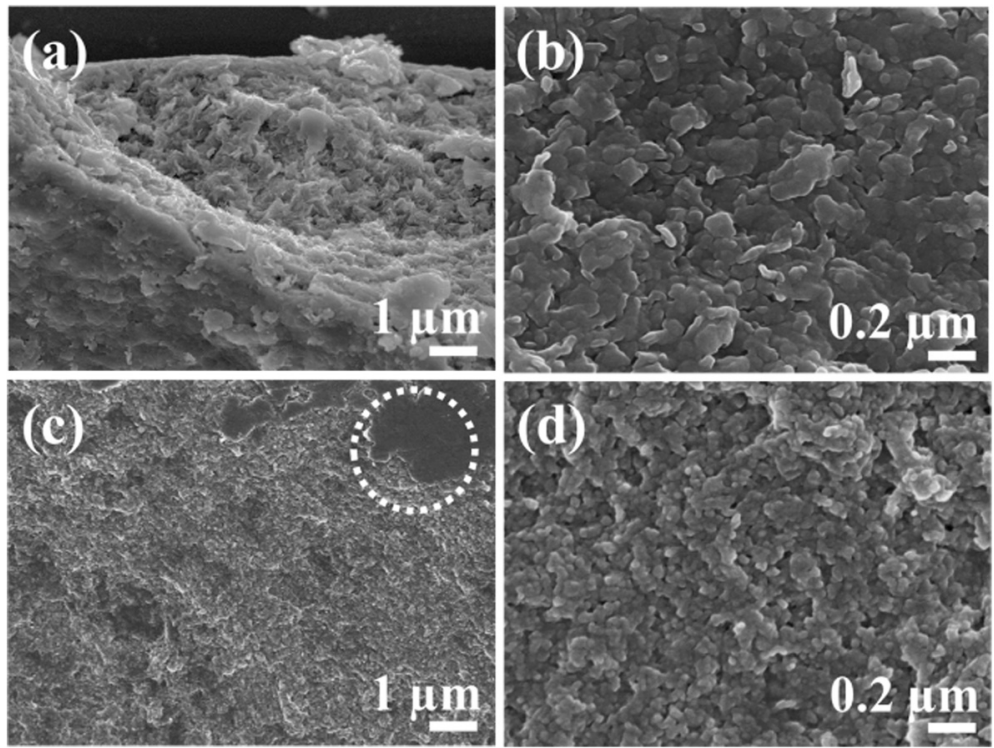

Fig. 3 FE-SEM images of (a), (b) coprecipitated ZnAl-LDH and (c), (d) agarose/LDH

$\mathrm{ZnAl}-\mathrm{LDH}$, might be attributed to the restricted crystal growth of LDH particles in the hydrogel polymer network.

Through various characterizations, we confirmed that a biopolymer/LDH hybrid with small and uniform ceramic LDH nanoparticles can be prepared by an electrophoretic method. Because both components of the hybrid (i.e., the biopolymer and LDH) are potential biomaterials, the resultant hybrid can be utilized in biomedical applications [25, 32]. Taking into account the fact that LDHs are attractive materials for sustained release drug delivery $[25,26]$, we attempted to investigate the drug release patterns of agarose/LDH and gelatin/ LDH hybrids. We chose an antioxidant agent (i.e., ferulic acid (FA)) because it has been reported that FA can be incorporated into LDH for drug delivery [33, 34]. In the experiments, lyophilized hybrids were soaked in an FA solution and again lyophilized. The samples showed FA contents of $49.93 \mathrm{wt} \%$ and $13.63 \mathrm{wt} \%$ for the agarose/ $\mathrm{LDH}$ and gelatin/LDH hybrids, respectively. Figure $4 \mathrm{a}$ shows the time-dependent and cumulative FA release curve for each hybrid, demonstrating releases of $26.09 \%$ and $71.41 \%$ after $2 \mathrm{~h}$ for agarose/LDH and gelatin/LDH, respectively. We fitted the time-dependent curves to well-known release kinetic curves, such as the first order Elovich equation, parabolic diffusion, and power function (data not shown). It was determined that only the Elovich model showed a coefficient of determinant $\left(\mathrm{r}^{2}\right)$ higher than 0.9. The Elovich model hypothesizes heterogeneous diffusion via the adsorption-desorption of ions and is often utilized to study the release kinetics of clay materials or LDHs $[35,36]$. Two constants $(\alpha$ and $\beta$ ) are important in Elovich model analysis; these are related to the initial release rate and the desorption kinetics, respectively [35]. It has been reported that sustained release systems exhibit small $\alpha$ and large $\beta$ values [16]. The $\alpha$ values of agarose/LDH and gelatin/LDH were determined to be 27.956 and 14.706, showing higher initial desorption of FA from agarose/LDH than from gelatin/ $\mathrm{LDH}$. The $\beta$ values were 0.2335 and 0.0681 for agarose/ $\mathrm{LDH}$ and gelatin/LDH, respectively, suggesting that agarose/LDH possesses superior sustained release properties. The different FA release kinetics of the two hybrids might be related to the polymer structure and polymer-LDH interactions inside of the hybrids. Agarose, which consists of polysaccharides with $\delta^{-}$sites, showed higher interaction with positive LDH nanoparticles compared to gelatin, which consists of polyaminoacids. The uniform distribution of LDH nanoparticles inside of the agarose matrix and the effective interaction between agarose and LDH can effectively block pathways of the FA molecules, reducing the total release amount and the release rate.

\section{Conclusions}

We prepared polymer/ceramic hybrid biomaterials via an electrophoretic preparation method. These materials are suitable for the homogeneous formation of ceramic nanoparticles in a hydrogel. We chose agarose and gelatin as the polymer component and LDH nanoparticles as the ceramic component. All of these materials have adequate biocompatibility and are widely applied in biomedical fields. We identified the crystal structure of LDH nanoparticles by XRD and 

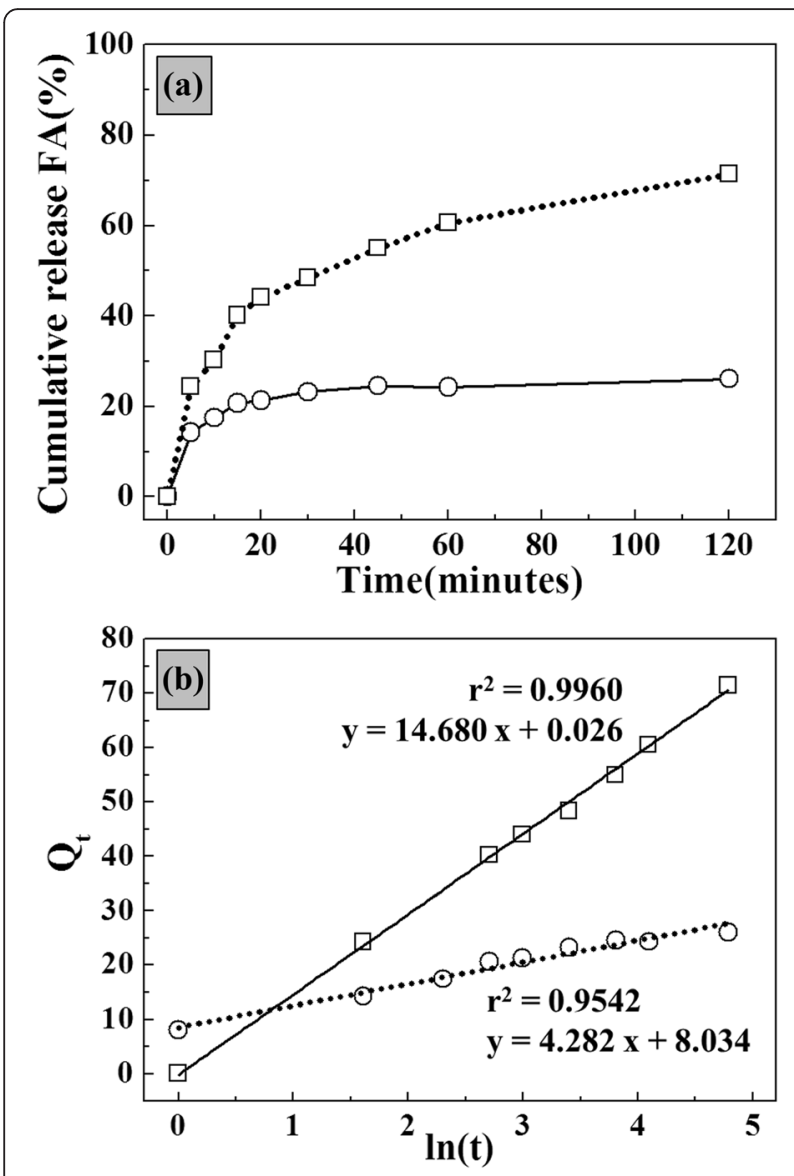

\begin{tabular}{|c|c|c|}
\hline & $\boldsymbol{\alpha}$ & $\boldsymbol{\beta}$ \\
\hline Agarose/LDH & 27.956 & 0.2335 \\
\hline Gelatin/LDH & 14.706 & 0.0681 \\
\hline
\end{tabular}

Fig. 4 a Time-dependent ferulic acid release patterns from agarose/ LDH (open circle) and gelatin/LDH (open square) and $\mathbf{b}$ their kinetic model fitting results and kinetic constants

XAS, which showed that the ceramic nanoparticles inside of the hybrid had the desired LDH structure. By analyzing SEM images, LDH nanoparticles were determined to be homogeneously formed in the hydrogel as we expected. Ferulic acid (the drug model molecule used in our study) was well-loaded onto the biopolymer/LDH hybrid and was released in a sustained manner.

\section{Competing interest}

The authors declare that they have no competing interest.

\section{Authors' contributions}

GHG carried out all of the experiments and drafted the manuscript. AJC participated in choosing the biopolymers and their treatment. YSB provided advice about the interactions between the biopolymers and ceramic nanoparticles. HJC discussed the interpretation of the X-ray diffraction patterns and the electron microscopic images. JMO discussed the results and commented on the manuscript. All authors read and approved the final manuscript.

\section{Acknowledgement}

This work was supported by a grant from the Postharvest Research Project (PJ010502) of RDA, Republic of Korea.

\section{Author details}

'Department of Chemistry and Medical Chemistry, College of Science and Technology, Yonsei University, \#326, Changjo-hall, Wonju Campus, Yonseidaegil 1, Heungeop-myeon, Wonju, Gangwondo 26493, Republic of Korea. ${ }^{2}$ Postharvest Research Team, National Institute of Horticultural and Herbal Science (NIHHS) of RDA, Wanju, Jeollabukdo 55365, Republic of Korea.

Received: 9 September 2015 Accepted: 4 January 2016

Published online: 10 February 2016

\section{References}

1. Tathe A, Ghodke M, Nikalje AP. A brief review: biomaterials and their application. Int J Pharm Pharm Sci. 2010;2:19-23.

2. Patel NR, Gohil PP. A review on biomaterials: scope, applications \& human anatomy significance. Int J Emerging Technol Adv Eng. 2012;2:91-101.

3. Lee HB. Needs and opportunities for the biomaterials industry. Polym Sci Technol. 1994;5:566-76.

4. Griffith L. Polymeric biomaterials. Acta Mater. 2000:48:263-77.

5. Petzetakis N, Dove AP, O'Reilly RK. Cylindrical micelles from the living crystallization-driven self-assembly of poly (lactide)-containing block copolymers. Chem Sci. 2011;2:955-60.

6. Hayashi T. Biodegradable polymers for biomedical uses. Prog Polym Sci. 1994;19:663-702.

7. Phadke A, Zhang C, Hwang Y, Vecchio K, Varghese S. Templated mineralization of synthetic hydrogels for bone-like composite materials: Role of matrix hydrophobicity. Biomacromolecules. 2010;11:2060-8.

8. Shih Y-RV, Hwang Y, Phadke A, Kang H, Hwang NS, Caro EJ, et al. Calcium phosphate-bearing matrices induce osteogenic differentiation of stem cells through adenosine signaling. Proc Natl Acad Sci. 2014;111:990-5.

9. Holmes RE. Bone regeneration within a coralline hydroxyapatite implant. Plast Reconstr Surg. 1979:63:626-33.

10. Staiger MP, Pietak AM, Huadmai J, Dias G. Magnesium and its alloys as orthopedic biomaterials: a review. Biomaterials. 2006;27:1728-34.

11. Narayan R. Biomedical materials, Springer Science \& Business Media. 2009. pp. 41-81.

12. Choi YS, Lee S, Hong SR, Lee Y, Song K, Park M. Studies on gelatin-based sponges. Part III: a comparative study of cross-linked gelatin/alginate, gelatin/hyaluronate and chitosan/hyaluronate sponges and their application as a wound dressing in full-thickness skin defect of rat. J Mater Sci Mater Med. 2001:12:67-73.

13. Cao Z, Gilbert RJ, He W. Simple Agarose-Chitosan Gel Composite System for Enhanced Neuronal Growth in Three Dimensions. Biomacromolecules. 2009; 10:2954-9.

14. Du C, Cui F, Feng Q, Zhu X, de Groot K. Tissue response to nanohydroxyapatite/collagen composite implants in marrow cavity. J Biomed Mater Res. 1998:42:540-8.

15. Ito Y, Hasuda H, Kamitakahara M, Ohtsuki C, Tanihara M, Kang I-K, et al. A composite of hydroxyapatite with electrospun biodegradable nanofibers as a tissue engineering material. J Biosci Bioeng. 2005;100:43-9.

16. Gwak GH, Paek SM, Oh JM. Electrophoretic Preparation of an OrganicInorganic Hybrid of Layered Metal Hydroxide and Hydrogel for a Potential Drug-Delivery System. Eur J Inorg Chem. 2012;2012:5269-75.

17. Alaminos M, Sánchez-Quevedo MDC, Munoz-Ávila Jl, Serrano D, Medialdea S, Carreras I, et al. Construction of a complete rabbit cornea substitute using a fibrin-agarose scaffold. Invest Ophthalmol Vis Sci. 2006;47:3311-7.

18. Mauck RL, Soltz MA, Wang CC, Wong DD, Chao P-HG, Valhmu WB, et al. Functional tissue engineering of articular cartilage through dynamic loading of chondrocyte-seeded agarose gels. J Biomech Eng. 2000;122:252-60.

19. Campo VL, Kawano DF, da Silva DB, Carvalho I. Carrageenans: Biological properties, chemical modifications and structural analysis-A review. Carbohydr Polym. 2009;77:167-80.

20. Edwards C, Blackburn N, Craigen L, Davison P, Tomlin J, Sugden K, et al. Viscosity of food gums determined in vitro related to their hypoglycemic actions. Am J Clin Nutr. 1987;46:72-7.

21. Wang L, Shelton R, Cooper P, Lawson M, Triffitt J, Barralet J. Evaluation of sodium alginate for bone marrow cell tissue engineering. Biomaterials. 2003; 24:3475-81. 
22. Tasneem M, Siddique F, Ahmad A, Farooq U. Stabilizers: Indispensable substances in dairy products of high rheology. Crit Rev Food Sci Nutr. 2014; 54:869-79.

23. Oh EJ, Park K, Kim KS, Kim J, Yang J-A, Kong J-H, et al. Target specific and long-acting delivery of protein, peptide, and nucleotide therapeutics using hyaluronic acid derivatives. J Control Release. 2010;141:2-12.

24. Cavani F, Trifirò F, Vaccari A. Hydrotalcite-type anionic clays: Preparation, properties and applications. Catal Today. 1991;11:173-301.

25. Choy J-H, Jung J-S, Oh J-M, Park M, Jeong J, Kang Y-K, et al. Layered double hydroxide as an efficient drug reservoir for folate derivatives. Biomaterials. 2004;25:3059-64.

26. Khan Al, Lei L, Norquist AJ, O'Hare D. Intercalation and controlled release of pharmaceutically active compounds from a layered double hydroxide. Chem Commun. 2001;2001:2342-3.

27. Foord S, Atkins E. New x-ray diffraction results from agarose: Extended single helix structures and implications for gelation mechanism. Biopolymers. 1989;28:1345-65.

28. Ki CS, Baek DH, Gang KD, Lee KH, Um IC, Park YH. Characterization of gelatin nanofiber prepared from gelatin-formic acid solution. Polymer. 2005: 46:5094-102.

29. Woo MA, Song M-S, Kim TW, Kim IY, Ju J-Y, Lee YS, et al. Mixed valence $\mathrm{Zn}$-Co-layered double hydroxides and their exfoliated nanosheets with electrode functionality. J Mater Chem. 2011;21:4286-92.

30. Hennig C, Hallmeier K-H, Zahn G, Tschwatschal F, Hennig H. Conformationa influence of dithiocarbazinic acid bishydrazone ligands on the structure of zinc (II) complexes: a comparative XANES study. Inorg Chem. 1999;38:38-43.

31. Choy J-H, Kwon Y-M, Han K-S, Song S-W, Chang SH. Intra-and inter-layer structures of layered hydroxy double salts, $\mathrm{Ni}_{1-x} \mathrm{Zn} \mathrm{n}_{2 x}(\mathrm{OH})_{2}\left(\mathrm{CH}_{3} \mathrm{CO}_{2}\right)_{2 x}$. $\mathrm{nH}_{2} \mathrm{O}$. Mater Lett. 1998;34:356-63.

32. Li Y, Rodrigues J, Tomas H. Injectable and biodegradable hydrogels: gelation, biodegradation and biomedical applications. Chem Soc Rev. 2012; 41:2193-221.

33. Oh J-M, Biswick TT, Choy J-H. Layered nanomaterials for green materials. J Mater Chem. 2009;19:2553-63.

34. Lima E, Flores J, Cruz AS, Leyva-Gómez G, Krötzsch E. Controlled release of ferulic acid from a hybrid hydrotalcite and its application as an antioxidant for human fibroblasts. Microporous Mesoporous Mat. 2013;181:1-7.

35. Chein S, Clayton W. Application of Elovich equation to the kinetics of phosphate release and sorption in soil. J Am Soil Sci Soc. 1980:44:265-8.

36. Yang J-H, Han Y-S, Park M, Park T, Hwang S-J, Choy J-H. New inorganicbased drug delivery system of indole-3-acetic acid-layered metal hydroxide nanohybrids with controlled release rate. Chem Mater. 2007;19:2679-85.

\section{Submit your next manuscript to BioMed Central and we will help you at every step:}

- We accept pre-submission inquiries

- Our selector tool helps you to find the most relevant journal

- We provide round the clock customer support

- Convenient online submission

- Thorough peer review

- Inclusion in PubMed and all major indexing services

- Maximum visibility for your research

Submit your manuscript at www.biomedcentral.com/submit 